\title{
A pandemia de COVID-19: securitização, crise neoliberal e a vulnerabilização global
}

\author{
The COVID-19 pandemic: securitization, neoliberal \\ crisis, and global vulnerabilization
}

\author{
La pandemia de COVID-19: securitización, crisis \\ neoliberal y la vulnerabilización global
}

João Nunes 1

doi: 10.1590/0102-311X00063120

\begin{abstract}
Neste artigo, situo a pandemia da doença do coronavírus (COVID-19) num cenário de securitização da saúde global. Abordo a pandemia como uma crise do modelo econômico neoliberal e como resultado de um processo de vulnerabilização decorrente do neoliberalismo. Essa pandemia nos convoca a repensar as vulnerabilidades resultantes da interconexão global. Sublinho a importância da saúde pública e participada no contexto de uma reflexão acerca das possibilidades de uma vida solidária e sustentável à escala global.
\end{abstract}

\section{Securitização e a crise do neoliberalismo}

A securitização se tornou nos últimos anos uma das mais importantes lentes interpretativas da saúde global 1. Descrevendo uma modalidade específica do nexo entre saúde e segurança, essa teoria defende que o estatuto de "ameaça" resulta de uma interação entre um ator que tenta definir um assunto como ameaça existencial, e uma audiência que aceita ou não esta tentativa. O que distingue um processo de securitização é a defesa de medidas extraordinárias - incluindo a suspensão ou exceções aos processos normais de deliberação democrática - como respostas necessárias a essa ameaça existencial 2. Esse recorte analítico tem sido utilizado para analisar casos como a SARS, a gripe das aves, o Ebola e a Zika, entre outros 3,4,5.

A COVID-19 confirma a dinâmica de securitização da saúde global. A pandemia foi abordada no quadro de uma ameaça à vida das pessoas e ao funcionamento regular das sociedades. Não se tratou de uma securitização da doença, que para a maioria dos infetados é assintomática ou de sintomatologia moderada. Porém, a COVID-19 apresenta uma taxa de letalidade mais elevada do que a da gripe A; tem um período de incubação de 1 a 14 dias; e é transmitida comunitariamente (e possivelmente durante o período assintomático) por gotículas de tosse e expetoração, e também por contato com superfícies ou objetos contaminados 6,7. Dadas essas especificidades, observou-se, isto sim, uma securitização da circulação de pessoas e do contato social, ou seja, dos fatores que poderiam levar a um crescimento exponencial do número de casos graves e, em consequência, ao colapso dos serviços de assistência. Em muitos países, a resposta configurou um cenário de exceção, com políticas de confinamento e distanciamento social. Declarações de emergência trouxeram poderes acrescidos
1 University of York, York, U.K.

Correspondência

J. Nunes

University of York.

YO10 5DD, York, U.K. joao.nunes@york.ac.uk 
às autoridades e, em alguns países, levaram a uma militarização da resposta. Salvo alguns casos, essa exceção foi aceita pela sociedade.

A securitização da circulação e do contato é um dado novo que essa crise trouxe à saúde global. Historicamente, a governança global da saúde tem como objetivo impedir que medidas nacionais de controle de doenças afetem de forma excessiva a circulação de pessoas e bens 8. Os Regulamentos Sanitários Internacionais de 2005, por exemplo, especificam em que circunstâncias os governos nacionais podem impor medidas de controle adicionais ao que é proposto internacionalmente. Os mecanismos de segurança sanitária surgiram como parte de uma mundividência liberal que visa instalar e manter uma triagem entre a circulação economicamente necessária (que deve ser promovida) e a circulação perniciosa para a economia ${ }^{9}$. Com a COVID-19, e apesar de as restrições à circulação não incluírem mercadorias e informação, a governança global da saúde sacrificou uma componente significativa da triagem, impondo severos limites à circulação economicamente necessária. O resultado foi um conjunto de consequências econômicas que poderão superar os efeitos da crise financeira de 2008.

A securitização, normalmente um mecanismo de proteção da economia, foi no caso da COVID-19 usada com fins contrários à economia. Não é por acaso que em países como o Brasil a resistência à securitização se baseou no argumento de que "a economia não pode parar". Esse argumento está correto, se o considerarmos como manifestação do que já foi apelidado de "neoliberalismo epidemiológico" 10. Tal como está organizada na sua forma neoliberal, a economia não pode suportar uma suspensão, ainda que temporária, da circulação. A COVID-19 revela a falta de resiliência do neoliberalismo, exposto a um choque global, e de grande magnitude, com origem num setor não econômico ou não financeiro. Mais do que isso, a pandemia demonstra as contradições do neoliberalismo, que exige circulação mesmo quando esta comprovadamente promove o adoecimento e a morte de uma porcentagem significativa da população. Trata-se, portanto, não só de uma crise de saúde pública, mas também de uma crise do modelo neoliberal. O capitalismo tem sido notável na sua reinvenção ao longo dos séculos, incorporando críticas em diversas ocasiões para se fortalecer 11. Uma nova reinvenção é possível. É também possível que se mantenha a ilusão de que a normalidade neoliberal pode ser reposta. Mas não temos muito tempo. Numa situação de emergência climática, em que se torna cada vez mais evidente a insustentabilidade de um modelo econômico baseado no crescimento ininterrupto, no consumo, no desperdício e na destruição da biodiversidade, as consequências da COVID-19 podem ser um prenúncio do futuro.

\section{A vulnerabilização global}

A pandemia de COVID-19 não significa apenas uma crise do neoliberalismo como modelo econômico, mas é também, ela mesma, uma crise de natureza neoliberal. A trajetória histórica da saúde global pode ser interpretada na ótica da expansão do neoliberalismo, em especial a partir da década de 198012. O neoliberalismo, baseado "na primazia do mercado, na competição, na intervenção estatal mínima e na eficiência do setor privado” 13 (p. 5), concretizou-se em políticas de ajustamento estrutural focadas na contenção da despesa pública, que por sua vez resultaram na desorçamentação e desmantelamento de sistemas públicos de saúde em todo o mundo. Essa tendência foi agravada pela crise financeira de 2008, à qual muitos governos responderam com políticas de austeridade que deram um novo impulso ao projeto neoliberal de deslegitimação da saúde como bem comum. As consequências no nível da degradação dos indicadores de saúde estão bem documentadas 14,15 .

Para além desses efeitos adversos, o neoliberalismo resultou numa vulnerabilização global face a choques epidêmicos como a COVID-19. Nesse contexto, a pandemia é um fenômeno político com as suas raízes no nosso passado recente neoliberal. A história da COVID-19 é feita de ações e omissões, ao longo das últimas décadas, que reduziram a capacidade dos sistemas de saúde de vigiar, conter e mitigar epidemias. Faz-se de escolhas políticas que acentuaram a desigualdade econômica, a precariedade do trabalho e o enfraquecimento de serviços públicos de assistência, o que por sua vez colocou uma parte significativa da população em situação de vulnerabilidade à doença e incapacidade de lidar com as suas consequências. Ao mesmo tempo, a história dessa pandemia é feita de dinâmicas socioeconômicas e culturais no nível da organização do trabalho e das relações sociais 16,17. Culturalmente, o neoliberalismo reflete-se na atomização social, na promoção do individualismo e da competitividade, 
e na destruição de redes de solidariedade e empatia essenciais ao esforço conjunto que a resposta à COVID-19 tornou necessário.

A vulnerabilidade é uma das problemáticas mais relevantes dessa pandemia, que mostrou como a saúde de cada um está dependente das ações e omissões de outros, e como a busca da invulnerabilidade total é uma ilusão. Até certo ponto, a vulnerabilidade é inevitável, resultando da frágil condição corpórea e do caráter social da vida humana 18. A crescente interconexão e interdependência globais, reforçadas pela globalização do capitalismo, somaram a essa vulnerabilidade ao aproximarem as sociedades e aumentarem a capacidade humana de infligir danos além-fronteiras 19. A COVID-19 demonstrou a acentuada vulnerabilização da vida cotidiana no capitalismo neoliberal. À vulnerabilidade inevitável o neoliberalismo adicionou sucessivas camadas de vulnerabilidade "patogênica", baseadas em "relações interpessoais e sociais moralmente disfuncionais ou abusivas, $e$ [em] opressão ou injustiça sociopolítica" 20 (p. 9). A desigualdade, a precaridade, a privatização da saúde, entre outros fenômenos, revelam a dinâmica neoliberal de exploração que subjaz a nossa vulnerabilidade a pandemias como a COVID-19.

Um outro aspeto relevante da vulnerabilidade é o fato de ela não ser uniforme. A COVID-19, como fato social global (facilitado pela circulação de informação nas redes sociais), pode fazer-nos acreditar que existe uma igualdade de condições. Uma das narrativas mais populares da saúde global é justamente a ideia de que estamos "unidos pelo contágio" 21. Mas não nos enganemos. Essa não é uma única pandemia, mas antes várias experiências de pandemia. Não estamos "todos juntos nisto": como homem, branco, recolhido confortavelmente em casa enquanto recebo um salário, eu não posso comparar a minha experiência com a de uma pessoa com profissão precária, ou impossibilitada de trabalhar e receber, ou em situação de rua. A vulnerabilidade é uma relação política desigual, por meio da qual determinados grupos - definidos em termos da identificação de gênero, raça, orientação sexual, idade, entre outros, bem como nas suas várias interseções 22 - são sistematicamente expostos ao empobrecimento, ao adoecimento e à morte.

\section{Conclusão}

A pandemia de COVID-19 tem um significado histórico importante, ao situar-se na confluência de duas dinâmicas globais interligadas - o neoliberalismo e a emergência climática - cujo caráter destrutivo obriga a repensar a organização das sociedades, a nossa relação com outros seres humanos e com o planeta 23.

A primeira lição da COVID-19 é a necessidade de uma reabertura política. Parte da força do neoliberalismo é sua fachada de inevitabilidade, pois está apoiada na ideia de que não existe alternativa à austeridade que visa a esvaziar o Estado como garantia do bem comum. Essa pandemia demonstra que a verdadeira resiliência não está no mercado (que é, normalmente, o primeiro a colapsar quando ocorre um choque de grande dimensão), nem na saúde privatizada. A resiliência está no fortalecimento de um sistema público e universal, apoiado no pressuposto da saúde como bem comum e na participação social como mecanismo democrático essencial para sua definição e implantação.

A segunda lição é a necessidade de uma consciência de limites e de finitude. A trajetória da COVID-19 e as suas consequências de curto e longo prazos dependem, não apenas de um neoliberalismo abstrato, mas de comportamentos individuais: a decisão de ficar em casa ou sair; a informação que produzimos e compartilhamos; o que consumimos, quando, e em que quantidade; a escolha entre a solidariedade, a busca do interesse próprio ou a estigmatização dos outros; enfim, a nossa proximidade ou distância, tanto em termos físicos quanto éticos. Tal como no caso da emergência climática, mas com maior visibilidade, a crise da COVID-19 colocou-nos perante um desafio que se joga em grande medida nas escolhas individuais, mas que vai muito para além delas. Trata-se de conciliar o realinhamento das escolhas individuais com a definição de uma resposta coletiva à escala global. Fundamental na resposta a esse desafio será repensar os pressupostos de uma vida comum, solidária e sustentável, consciente da nossa vulnerabilidade compartilhada e da forma como esta vulnerabilidade se reflete em experiências múltiplas e desiguais. 


\section{Informação adicional}

ORCID: João Nunes (0000-0002-0118-0993).

\section{Referências}

1. Ventura DFL. Do Ebola ao Zika: as emergências internacionais e a securitização da saúde global. Cad Saúde Pública 2016; 32:e00033316.

2. Buzan B, Wæver O, De Wilde J. Security: a new framework for analysis. Boulder: Lynne Rienner Publishers; 1998.

3. Curley MG, Herington J. The securitisation of avian influenza: international discourses and domestic politics in Asia. Rev Int Stud 2011; 37:141-66.

4. Enemark C. Ebola, disease-control, and the Security Council: from securitization to securing circulation. Journal of Global Security Studies 2017; 2:137-49.

5. Wenham C, Farias DB. Securitizing Zika: the case of Brazil. Secur Dialogue 2019; 50:398415.

6. Anderson RM, Heesterbeek H, Klinkenberg D, Hollingsworth TD. How will country-based mitigation measures influence the course of the COVID-19 epidemic? Lancet 2020; 395:931-4.

7. World Health Organization. Modes of transmission of virus causing COVID-19: implications for IPC precaution recommendations. https://www.who.int/news-room/commen taries/detail/modes-of-transmission-of-viruscausing-covid-19-implications-for-ipc-pre caution-recommendations (acessado em 27/ Mar/2020)

8. King NB. Security, disease, commerce: ideologies of postcolonial global health. Soc Stud Sci 2002; 32:763-89.

9. Foucault M. Security, territory, population: lectures at the Collège de France, 1977-78. Houndmills: Palgrave MacMillan; 2007.

10. Frey I. "Herd immunity" is epidemiological neoliberalism. https://thequarantimes.word press.com/2020/03/19/herd-immunity-is-ep idemiological-neoliberalism/ (acessado em 27/ Mar/2020).

11. Boltanski L, Chiapello E. Le nouvel esprit du capitalisme. Paris: Gallimard; 1999.
12. Keshavjee S. Blind spot: how neoliberalism infiltrated global health. Berkeley: University of California Press; 2014.

13. Harman S. Global health governance. Abingdon: Routledge; 2011.

14. Schrecker T, Bambra C. How politics makes us sick: neoliberal epidemics. Houndmills: Palgrave MacMillan; 2015.

15. Labonté R, Stuckler D. The rise of neoliberalism: how bad economics imperils health and what to do about it. J Epidemiol Community Health 2016; 70:312-8.

16. Sennett R. The corrosion of character: the personal consequences of work in the new capitalism. New York: WW Norton \& Company; 1998.

17. Scharff C. The psychic life of neoliberalism: mapping the contours of entrepreneurial subjectivity. Theory Cult Soc 2016; 33:107-22.

18. Butler J. Undoing gender. Abingdon: Routledge; 2004.

19. Linklater A. The problem of harm in world politics: theoretical investigations. Cambridge: Cambridge University Press; 2011.

20. Mackenzie C, Rogers W, Dodds S. Introduction: what is vulnerability and why does it matter for moral theory? In: Mackenzie C, Rogers W, Dodds S, editors. Vulnerability: new essays in ethics and feminist philosophy. Oxford: Oxford University Press; 2014. p. 1-29.

21. Zacher M, Keefe TJ. The politics of global health governance: united by contagion. Houndmills: Palgrave MacMillan; 2008.

22. Crenshaw K. Mapping the margins: intersectionality, identity politics, and violence against women of color. Stanford Law Rev 1990; 43:1241-99.

23. Ventura DFL, Ribeiro H, di Giulio G, Jaime P, Nunes J, Bógus C, et al. Desafios da pandemia de COVID-19: por uma agenda brasileira de pesquisa em saúde global e sustentabilidade. Cad Saúde Pública 2020; 36:e00040620. 